\title{
Actual state of knowledge in the field of Supply Chain Management
}

\author{
Oana Dumitrascu, ${ }^{1, *}$, and Constantin Manuel Hila ${ }^{1}$ \\ ${ }^{1}$ University of "Lucian Blaga", Faculty of Engineering, 550025, Sibiu, Emil Cioran street, No. 4, \\ Romania
}

\begin{abstract}
This paper aims to analyse the actual state of research in the field of supply chain management and to identify eventual gaps of knowledge and potential research directions in the field concerned. Concepts such as supply chain, supply chain management, procurement management, sales management, outsourcing, quality standards, key performance indicators and data visualisation are analysed and defined. Defining conceptual elements of the approached field, analysing different national and international studies, converge to identify eventual differences concerning authors' opinion, problems, research gaps and potential research directions. It has been found that the specialty literature analyses in general subjects such as supply chain management, supplier performance, suppliers' selection and evaluation, suppliers' development, performance management and do not take into consideration also the supply chain management performance, so that various gaps concerning the specialty literature in the field of supply chain management performance evaluation have been identified. Causes, effects and hypothetical solutions of the identified problems have been highlighted.
\end{abstract}

\section{Introduction}

Due to a previous work, the state of art in the field of supply chain management is presented through a bibliographic study that is conducted from various secondary sources. Through the benchmarking method best practices in this field are identified. Based on this research, specific terms, concepts, definitions related to this field, typology and orientation of existing specialised studies in the scientific literature were analysed. The main goal of this paper was to analyse the actual state of the scientific knowledge in the field of supply chain management and to ascertain the eventual gaps of knowledge in this area, identifying potential unexplored research directions.

In the first part of research, the epistemological approach and conceptual elements were presented. Concepts such as supply chain, supply chain management, procurement management, sales management, outsourcing, performance management and data visualisation were analysed and defined.

The concept of supply chain management is seen as a philosophy with a purpose to integrate the independent activities, material and human resources from the point of origin

* Corresponding author: oana.dumitrascu@ulbsibiu.ro 
to final destination. Thus, the Supply Chain Management (SCM) can be defined as an integrated, strategic coordination of the organisation's functions, processes and transactions within the supply chain, with an overall goal of improving long-term performance and gain a competitive edge on the market, [1].

Procurement by definition represents the process of obtaining goods and services from preparation and processing of a requisition through to receipt and approval of the invoice for payment. Purchasing is responsible for acquiring all the materials needed by an organisation. Purchasing is the function responsible for issuing purchase orders and initiating the flow of materials, [2].

Sales management is presented as a complex unitary process, attached to which is an extended structure of specific activities that are aimed at the problems of leadership coordination, forecast - planning, scheduling, organizing, contracting - selling products, training, monitoring and checking the status - realisation of the activity, analysing and evaluating results, [3].

The phenomenon of outsourcing is increasingly encountered today. By outsourcing we understand the transfer of employees, know-how, assets or the transfer of various services from one company to another in order to streamline the process and thus reduce costs, placing also focus on companies' specialisation within their maximum competence field.

It is the authors' opinion that Supply Chain Management leads to operational effectiveness and therefore is critical that organisations manage it properly. Without a proper management of strategic and operational performance of the supply chain, organisations will not be able to achieve their strategic objectives.

Data visualisation lays at the intersection of the study of human cognition and perception, advances in technology, graphical interfaces, extensive implementation of standards for internet applications, and the ongoing increase of interest and experience in analytics and data discovery, [4]. In our point of view, data visualisation plays a very important role when it comes to evaluate supply chain management performance. This can be evaluated by means of specific key performance indicators visualised in dashboards or scorecards, that improves supervising and conducting the entire supply chain management process and increases its performance.

When managed in a proper manner, supply chain performance ensures the strategic objectives derived from the organisations' strategy. This involves measuring, communicating, benchmarking performance, setting performance targets, managing issues and risks, leading improvements and changes, and fostering stakeholder.

In the bibliographical study various sources were used, such as [5-13].

In the epistemological approach and research state of scientific knowledge, specific terminology and conceptual elements are treated. The supply chain management concept is analysed, highlighting the characteristics of the procurement and sales management.

Concerning the concept of supply chain management and its performance evaluation a lack of knowledge in this field can be identified. The specialty literature includes various studies on supply chain management, supplier development, supplier performance evaluation, performance management, but does not link these research directions to the supply chain management performance evaluation, so that a certain knowledge gap in the national and international literature is identified. Concerning the authors' opinion, it is highly recommended that the specialty literature in this field should be developed by linking these fields together.

Many studies aim to analyse the supply chain management. It is shown how supply chain management has become a very important tool set concerning the solution that are offered for supply chain planning, execution, coordination, and also collaboration. [14]

Another research direction is the one focusing on supplier development. Proch, Worthmann and Schluchtermann (2016) point out how to coordinate supplier development 
in supply chains. The [16] analyses Toyota's supplier development practices. Dalvi and Kant (2015) analyses the crucial benefits of supplier development, such as effective supply chain management, efficient communication, strategic benefits, delivery performance, competitive advantages, cost reduction and supplier's performance. [15-17]

Another research direction focuses on performance evaluation. Some studies focus on supplier performance evaluation and selection. Schmitz and Plattz (2004) indicate the importance of performance evaluation of suppliers. [18]

Some studies analyse also the supply chain management performance. In [6] shows that a good implementation of supply chain management can lead to positive outcomes such as on-time deliveries, product quality, reduce wastage and inventory and low operating costs. [6]

Taking into consideration the dynamic field of supply chain management and analysing various international bibliographical sources, it can be affirmed that presently there is a vast number of theoretical models and principles companies can follow and implement. Current studies focus mainly on the process of logistics in general, taken as a whole, or on the supply management in particular. Usually, performance aspects, their evaluation process, neither their methods of implementation in different environments and organisational cultures are not taking in consideration. In the authors' point of view, analysing diverse national bibliographical sources, a lack of specialty literature can be noticed, in the field of performance evaluation of supply chain management, but also in the field of supply chain management, supplier selection or supplier development. A few studies focus also on the evaluation of performance within the supply chain management system.

The second part of the report presents the bibliographic research from various nationally and internationally studies. Diverse bibliographical references have been consulted: $[14,19$, $5,15,16,17,20,21]$.

Both in the international literature and in the national various studies, scientific articles and books deal on the one hand presenting the goals and advantages of supply chain management and on the other hand analysing the aspects of supplier development and the influence factors on the supplier selection.

The third part of the research consists in identifying certain gaps, problems regarding the current state of scientific knowledge and analysis of causes, effects, hypothetical solutions of problems and defining of new objectives for future research.

\section{Analysis of causes, effects of problems in the field of supply chain management specialty literature}

Both in the international literature and in the national various studies, scientific articles and books deal on the one hand presenting the concept of supply chain management and on the other hand on presenting supplier performance, suppliers' evaluation, selection and performance management. Current studies focus mainly on the process of logistics in general, taken as a whole, or on the supply management in particular and do not take performance aspects, their methods of implementation in different environments and organisational cultures in consideration. In our opinion an important gap concerning the specialty literature in the field of supply chain management performance can be observed, so that it is recommended to develop different studies, including key performance indicators, dashboards and scorecards in the field of supply chain management. Also, certain studies in the field of supplier development including the purchasing research should be developed. 
It has been found that the specialty literature treats in general subjects such as supplier performance, suppliers' selection and evaluation, suppliers' development, performance management or supply chain management in general and do not focus also on the evaluation of performance within the supply chain management system.

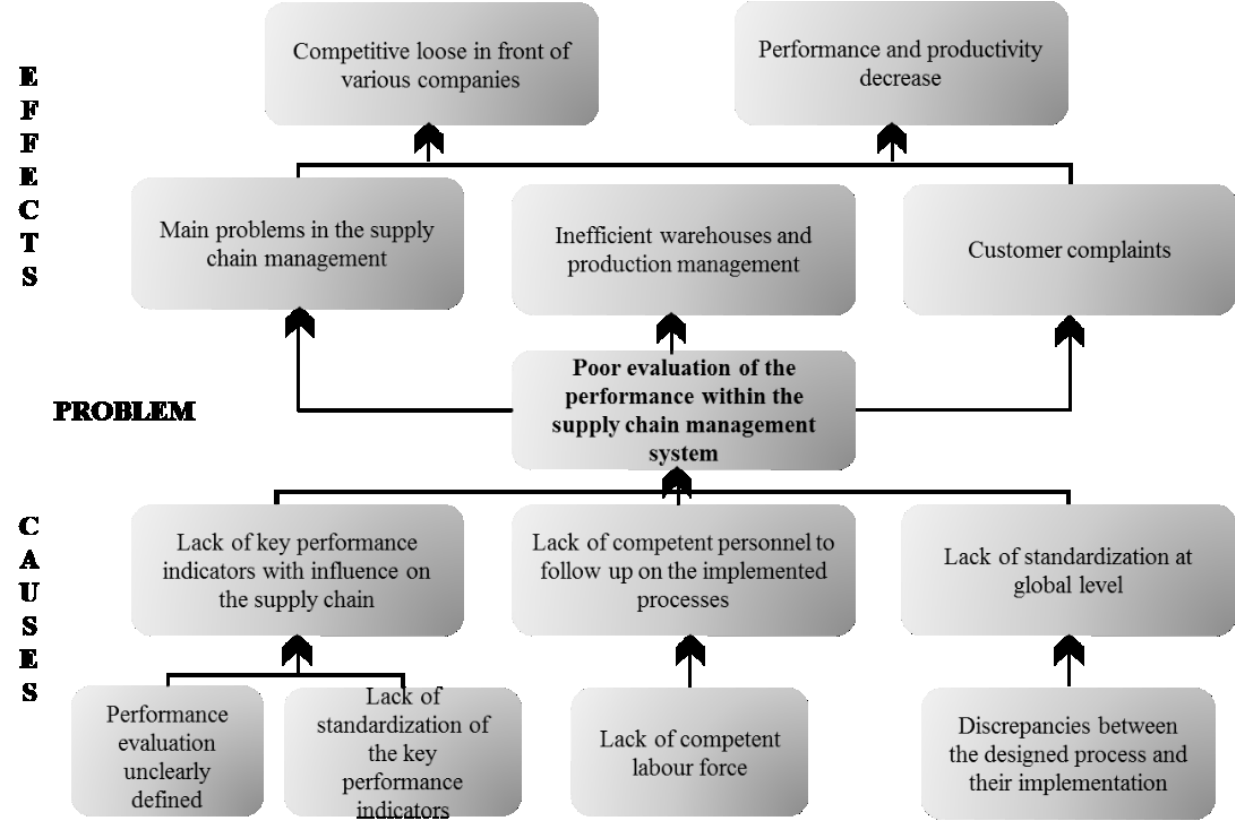

Fig. 1. Problem tree for identifying the causes and effects of the main identified problem

The presented problem tree (Figure 1) presents several causes that are leading to a poor evaluation of the supply chain management system, aspect which lead to the incapacity of performance measurement and thus to decreased productivity and efficiency.

In the authors' point of view starting from the issues identified in the problem tree, we can distinguish the main problem, the poor evaluation of the performance within the supply chain management system.

Certain issues were identified such as lack of performance indicators in the field of supply chain, caused by an unclearly defined performance evaluation and a lack of standardization of KPI's, lack of competent personnel to follow up the implemented process, due to the lack of competent labour force and due to lack of a global level standardisation, due to certain discrepancies between the designed process and their implementation.

A poor evaluation of the supply chain management performance can cause main problems in the supply chain management, can conduct to customer complaints and inefficient warehouses and production management that can lead to performance and productivity decrease and competitive loose in front of other companies.

\section{Analysis of hypothetical solutions of problems regarding the supply chain management specialty literature}

After analysing the problem and relationship between means and objectives, objectives are deducted and formulated with the role of finding potential solutions. 


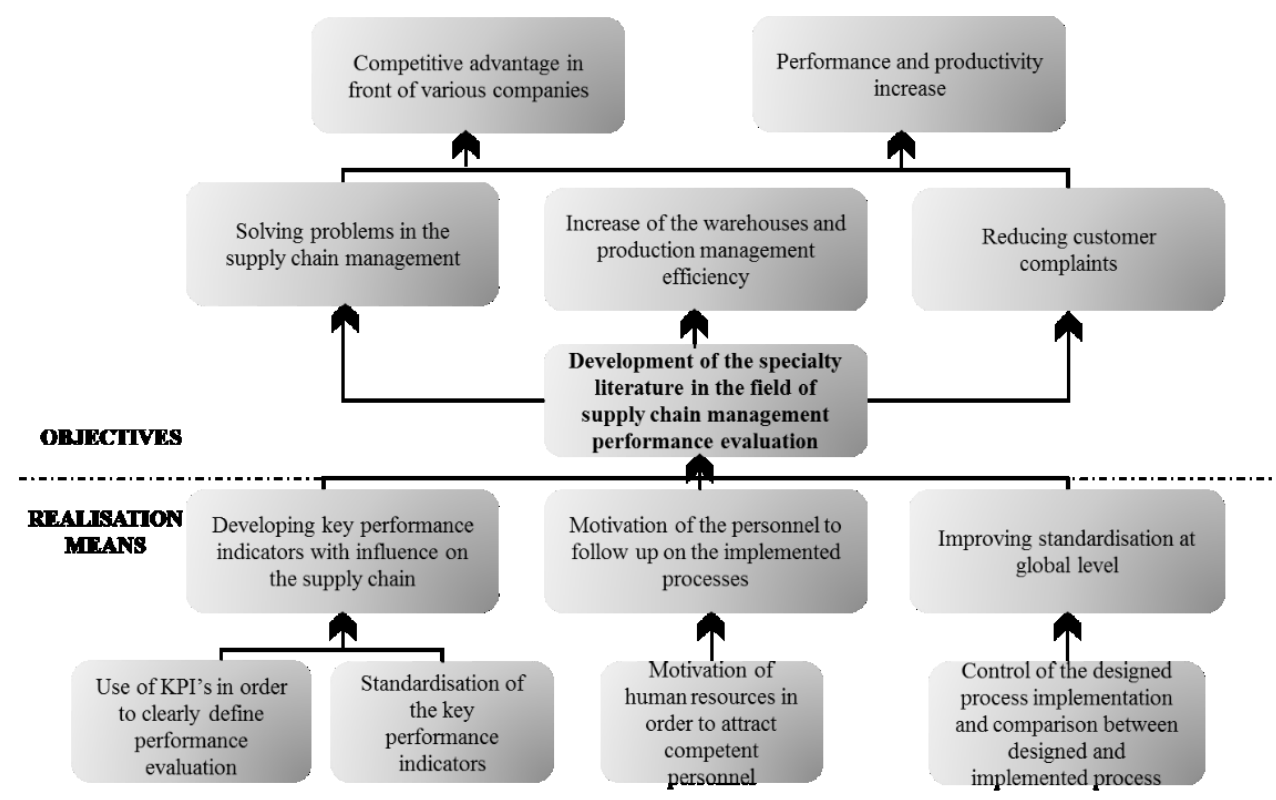

Fig. 2. Development of the relationship between objectives and realisation means

In our point of view, the main objective regarding the development of the specialty literature in the field of supply chain management performance evaluation can be achieved by developing key performance indicators with influence on the supply chain. The use of KPI's in order to define performance evaluation but also the standardisation of the KPI's could lead to this. The development of the specialty literature in this field could be reached as well by an increased motivation of the personnel in order to follow up on the implemented processes and by an improved standardisation at a global level, due to a control of the designed process implementation and comparison between designed and implemented process. These aspects will lead to an increase of the warehouse and production management efficiency, will reduce customer complaints and solving problems in the supply chain, that will increase the performance and productivity and bring a competitive advantage in front of various companies.

\section{Conclusions}

The work developed facilitated the analysis of the current state of research and of the conceptual elements specific of the field concerned by consulting numerous bibliographic sources, studies and researches, which led to the identification of problems, causes, effects and hypothetical solutions. Specific problems and potential solutions have been identified. This work forms the basis of future research, on the basis of the objectives and hypotheses set.

As specific objectives of a future research that converge to the achievement of the overall objective we can distinguish:

- Determination of the main problems in the supply chain management;

- Determination of the influence of supply chain management on quality, production, sales and procurement;

- Demonstrating specific correlations between supply chain management, performance management, key performance indicators, quality standards, lean planning, six sigma, just in time, Kanban and data visualisation; 
- Comparison of the supply chain management systems from various companies;

- Analysing the existing performance evaluation system based on key performance indicators in the studied companies;

- Improvement of the specialty literature in the interest domains, aspect that will fill the observed gaps by determining the link between the interest domains which lay within the supply chain management system.

The general objective of the future research is to bring new contributions regarding the performance evaluation of the supply chain management system, with a positive effect on improving the standardisation of the processes. This will contribute to the performance improvement of specific processes by increasing the capacity of performance evaluation, but also the adaptability of the process as to allow an easier implementation according to the needs and specifications.

\section{References}

1. J. Mentzer, S. Min, Z. Zacharia, Journal of Retailing, 76 (4), 549-568 (2000)

2. R. Monczka, et al., Purchasing and Supply Chain Management, 34-36, (South-Western Publisher, Mason, 2010)

3. S. Crişan, Managementul desfacerii, (Sibiu, 2013)

4. D. Stodder, Data visualization and discovery for better business decisions, The Data Warehousing Institute best practices report, (2013)

5. A. Agus, JGSM, 5 (1), 134-145 (2011)

6. A. Agus, JOEBM, 3 (11), $1046-1053$ (2015)

7. J. M. Aitken, Supply Chain Integration within the Context of a Supplier Association (Ph.D. thesis, Cranfield University, UK, 1998)

8. P. Baily, et al., Procurement principles and management, 10th edition, (Pearson Education Limited, Harlow, 2008)

9. M. Christopher, Logistics \& supply chain management, (Pearson Education Limited, Harlow, 2016)

10. S. Few, Data visualization for human perception, 2nd edition, (The Interaction Design Foundation, 9, 2014)

11. L. Johnson, F. Fearon, Purchasing and Supply Management: with 50 supply chain cases, 13th ed., (2006)

12. V. Lupşe, O. Cosma, Revista Informatica Economică 2 (38), 120 - 123 (available at: http://revistaie.ase.ro, 2006)

13. T. Uta, I.D. Ion, Analiza pieței de furnizare şi selecţia furnizorilor, Al treilea simpozion ECR Academic Partnership România, (available at: http://www.ecr-uvt.ro., 2009)

14. S. Bansal, Technology Scorecards: Aligning IT investments with Business Performance, 31-33, (John Wiley \& Sons, Inc., Hoboken. NJ, USA, 2009)

15. M. Proch, K. Worthmann, J. Schluchtermann, European Journal of Operational Research, 256 (2), 412-429, (2016)

16. P. Marksberry, Benchmarking: An International Journal, 19 (2), 277-298, (2012)

17. M. Dalvi, R. Kant, Asia Pacific Journal of Marketing and Logistics, 27 (4), 653-654 (available at: http://www. emeraldinsight.com/doi/abs/10.1108/APJML-11-2014-0161, 2015)

18. J. Schmitz, K. Platts, International Journal of Production Economics, 89 (2), 231-243, (available at:

https://www.researchgate.net/publication/4917445_Supplier_logistics_performance_measureme nt_indications_from_a astudy_in_the_automotive_industry_International_Journal_of_Production Economics_892_231-243, 2004)

19. $\bar{C}$. Martin, Logistics \& Supply Chain Management, Fourth Edition, (Pearson Publisher, Harlow, 2011)

20. A. Sanchez, M. Perez, International Journal of Operations \& Production Management, 25 (7), 681-700, (2005)

21. Gallego, L., Review of existing methods, models and tool for supplier evaluation, (Linkopings Universitet, Institute of Technology, 2011) 